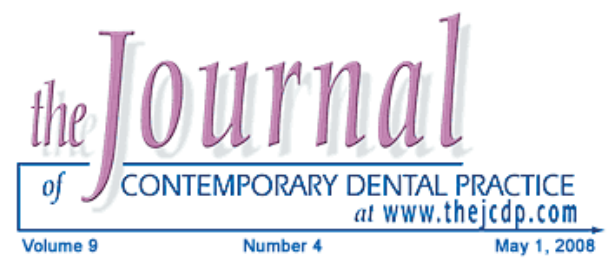

\title{
Ozone Therapy in Medicine and Dentistry
}

\author{
Carlos Goes Nogales, DDS; Patrícia Helena Ferrari, DDS, Ms, PhD; \\ Efraim Olszewer Kantorovich, DDS; \\ José Luiz Lage-Marques, DDS, Ms, PhD
}

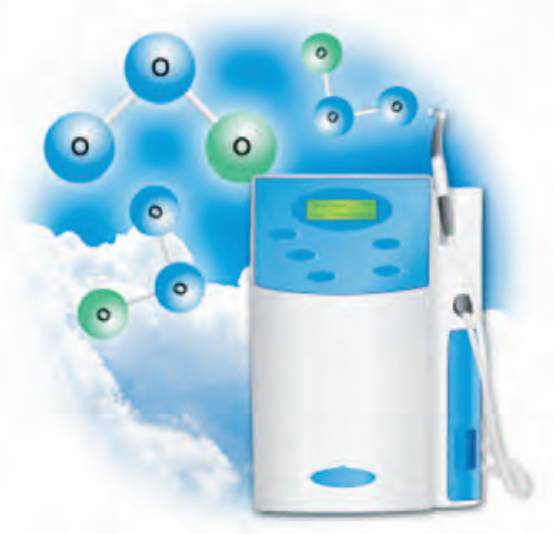

\section{Abstract}

Aim: The purpose of this review is to present the potential for the incorporation of ozone therapy into the practice of dentistry.

Background: Ozone gas has a high oxidation potential and is 1.5 times greater than chloride when used as an antimicrobial agent against bacteria, viruses, fungi, and protozoa. It also has the capacity to stimulate blood circulation and the immune response. Such features justify the current interest in its application in medicine and dentistry and have been indicated for the treatment of 260 different pathologies. It can be used for the treatment of alveolitis as a replacement for antibiotic therapy, as a mouthwash for reducing the oral microflora, as well as the adherence of microorganisms to tooth surfaces. Ozone has been shown to stimulate remineralization of recent caries-affected teeth after a period of about six to eight weeks.

Conclusion: The future of ozone therapy must focus on the establishment of safe and well-defined parameters in accordance with randomized, controlled trials to determine the precise indications and guidelines in order to treat various medical and dental pathologies. Scientific support, as suggested by demonstrated studies, for ozone therapy presents a potential for an atraumatic, biologically-based treatment for conditions encountered in dental practice.

Keywords: Ozone, ozone therapy, ozonated water

Citation: Nogales CG, Ferrari PA, Kantorovich EO, Lage-Marques JL. Ozone Therapy in Medicine and Dentistry. J Contemp Dent Pract 2008 May; (9)4:075-084.

(c) Seer Publishing 


\section{Introduction}

\section{Background ${ }^{1,2,3}$}

Ozone is a chemical compound consisting of three oxygen atoms $\left(\mathrm{O}_{3}\right.$ - triatomic oxygen), a higher energetic form than normal atmospheric oxygen $\left(\mathrm{O}_{2}\right)$. Thus, the molecules of these two forms are different in structure (Figure 1).

It is one of the most important gases in the stratosphere due its ability to filter UV rays which is critical for the maintenance of biological balance in the biosphere. This protective layer can be seen as the blue-colored sky.
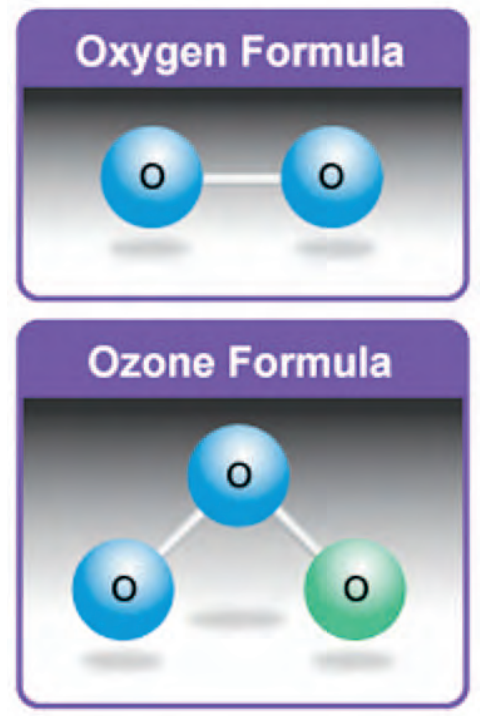

Figure 1. Oxygen and ozone formulas.
Ozone is produced naturally by the following natural methods:

- From electrical discharges following thunderstorms. Ozone is created when an oxygen molecule receives an electrical discharge breaking it into two oxygen atoms. The individual atoms combine with another oxygen molecule to form an $\mathrm{O}_{3}$ molecule (Figure 2).

- From ultraviolet rays emitted from the sun which plays the role of electrical discharge over oxygen present in the stratosphere, thus, creating the ozone layer which absorbs most of the ultraviolet radiation emitted by the sun.

Medical grade ozone is made from pure medical oxygen because oxygen concentration in the atmospheric air is variable. Atmospheric air is made up of nitrogen $(71 \%)$, oxygen ( $28 \%)$, and other gasses (1\%) including ozone which is altered by processes related to altitude, temperature, and air pollution.

There are three different systems for generating ozone gas:

- Ultraviolet System: produces low concentrations of ozone. It is used in esthetics, saunas, and for air purification.

- Corona Discharge System: produces high concentrations of ozone. It is the most common system used in the medical/ dental field. It is easy to handle and it has a controlled ozone production rate.

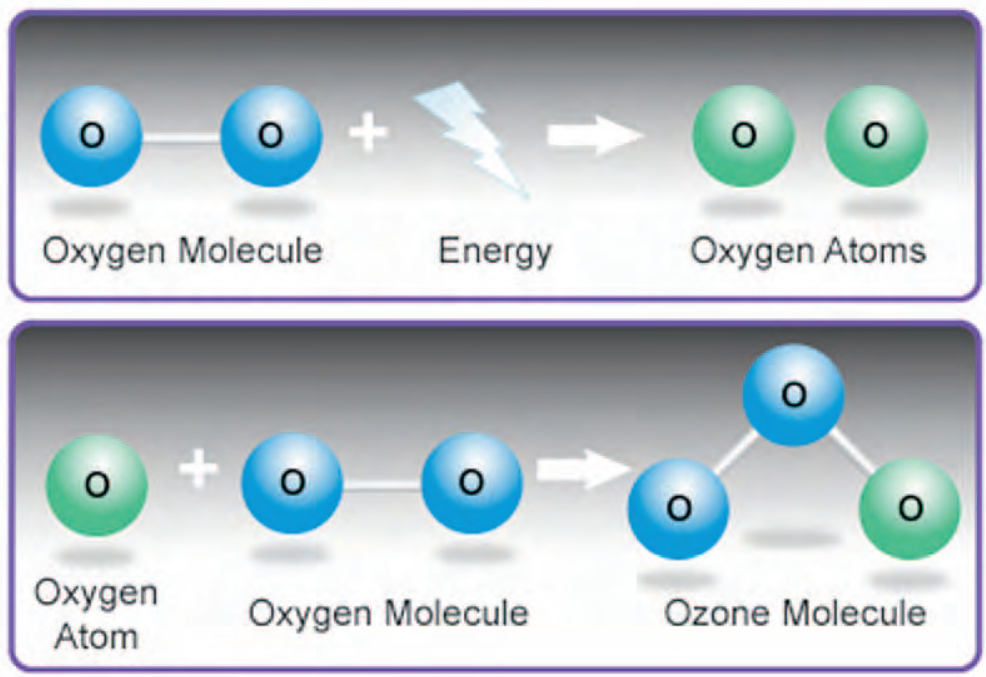

Figure 2. Production of ozone. 
- Cold Plasma System: used in air and water purification.

\section{Ozone for Medical-Dental Use}

\section{Brief History}

The German chemist Christian Friedrich

Schönbein is considered to be the father of ozone therapy (1840). When he passed an electrical discharge through water, a strange smell was produced, which he called Ozon, from the Greek word ozein (odor). Edward Fisch was the first dentist to use ozone in 1950. He used ozone to treat Austrian surgeon Ernst Payr who then became an ozone enthusiast and began a line of research dedicated to its use in healthcare. At the time, ozone therapy was difficult and limited due to the lack of ozone-resistant materials, such as Nylon, Dacron, and Teflon, until 1950 when ozone-resistant materials were manufactured. At that time Joachim Hänsler, a German physicist and physician, joined another German physician, Hans Wolff, to develop the first ozone generator for medical use. Their design continues to be the basis for modern equipment.

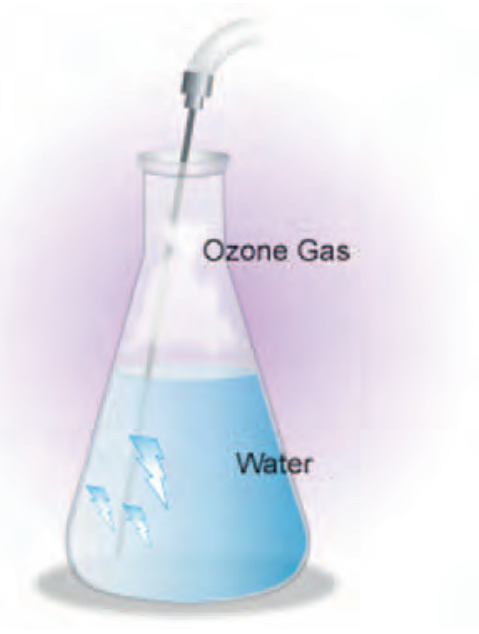

Medical grade ozone is a mixture of pure oxygen and pure ozone in the ratio of $0.05 \%$ to $5 \%$ of $\mathrm{O}_{3}$ and $95 \%$ to $99.95 \%$ of $\mathrm{O}_{2}$.

Due to the instability of the $\mathrm{O}_{3}$ molecule medical grade ozone must be prepared immediately before use. Within less than an hour after preparation only half of the mixture is still ozone while the other half is transformed into oxygen. As a result, it is impossible to store ozone over long periods of time. In order to control the decomposition of $\mathrm{O}_{3}$ into oxygen it can be associated with a vehicle with aqueous properties to promote the conversion more quickly or with a vehicle with more viscous properties to retard the conversion.

\section{Ozone Toxicity}

Ozone inhalation can be toxic to the pulmonary system and other organs. Known side-effects are epiphora and upper respiratory irritation, rhinitis, cough, headache, occasional nausea, and vomiting. However, complications caused by ozone therapy are infrequent at 0.0007 per application. In the event of an ozone intoxication the patient must be placed in the supine position, inhale humid oxygen, and take ascorbic acid, vitamin $\mathrm{E}$, and nacetylcysteine.

Because of ozone's highly oxidative power, all materials that come in contact with the gas must be ozone resistant, such as glass, silicon, and Teflon.

\section{Ozone Therapy Contraindications}

The following are contraindications for use of ozone therapy: ${ }^{3}$

- Pregnancy

- Glucose-6-phosphate-dehydrogenase deficiency (favism)

- Hyperthyroidism

- Severe anemia

- Severe myasthenia

- Active hemorrhage

\section{Methods of Administering Medical Ozone} Because of its high oxidative power and effect on bacteria, viruses, and fungi, ozone therapy is indicated in the treatment of 260 different pathologies. Systemic administration of ozone gas has been carried out using different methods as described below.

\section{Major Autohemotherapy}

This is an extracorporeal blood treatment with ozone gas followed by the intravenous reinfusion of the patient's treated blood. It is indicated for treatment of arterial circulatory disorders, infections, and for rheumatic arthritis. It is also useful in the promotion of immunoactivation, provides additive therapy for geriatric carcinoma patients. $^{1-4}$ 


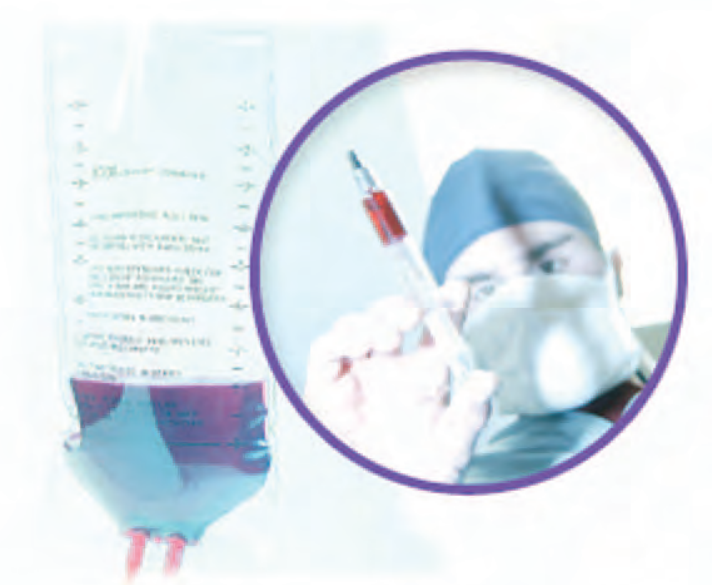

Autohemotherapy promotes:

- Activation of red blood cell metabolism with an increase of 2.3-diphosphoglycerate and Adenosine Triphosphate (ATP) plus improving $\mathrm{O}_{2}$-release to the tissues. ${ }^{4}$

- Activation of immunocompetent cells with release of cytokins, such as interferons and interleukins. ${ }^{4}$

\section{Minor Autohemotherapy}

This is an extracorporeal blood treatment and intramuscular injection. It is indicated for allergies, acne, furunculosis, and adjuvant cancer therapy. The mechanism of action deals with a nonspecific activation and general stimulation of the immune-system. . $^{1,2,3,4}$

\section{Rectal $\mathrm{O}_{3} / \mathrm{O}_{2}$ Insuflation}

This method of administration is indicated for arterial circulatory disorders (stage II), general immunoactivation, adjuvant cancer therapy, and hepatitis $A, B$, and $C$. The effects are virtually equal to those of major autohemotherapy. ${ }^{1-4}$

\section{The Use of Ozone in Dentistry}

Interest in ozone use in dentistry is due to the infectious diseases associated with the oral cavity. Ozone therapy presents great advantages when used as a support for conventional treatments, for example, to dental caries, periodontal procedures, and endodontic treatment. $^{3}$

\section{Dental Ozone Generators}

Recent studies have proven the effectiveness of applying ozone in both the medical and dental fields and its indications for use in a wide range of specialties. ${ }^{1,2,6-8,10-13,16,17,21,24,25}$
Application of ozone gas has been advocated in dentistry for sterilization of cavities, ${ }^{10,14,15}$ root canals, ${ }^{21-24}$ periodontal pockets, ${ }^{16}$ and herpetic lesions. ${ }^{25}$

CurOzone USA Inc. (Ontario, Canada) developed the HealOzone, which is now distributed by KaVo Dental (KaVo, Biberach, Germany), for use in dentistry.

Millar and Hodson ${ }^{5}$ compared the safety of two ozone generating systems. These are the Ozicure device (which is no longer available and is not licensed for use in Europe) and HealOzone developed by CurOzone USA Inc., now distributed by KaVo Dental, Biberach, Germany, for use in dentistry. The two were compared based on the amount of ozone that escaped during gas application. The investigators found the Ozi-cure device, when used without adequate suction, allowed ozone to reach concentrations above the permitted levels and, therefore, should not be used. The HealOzone generator was found to be safe to use following the manufacturer's recommendations.

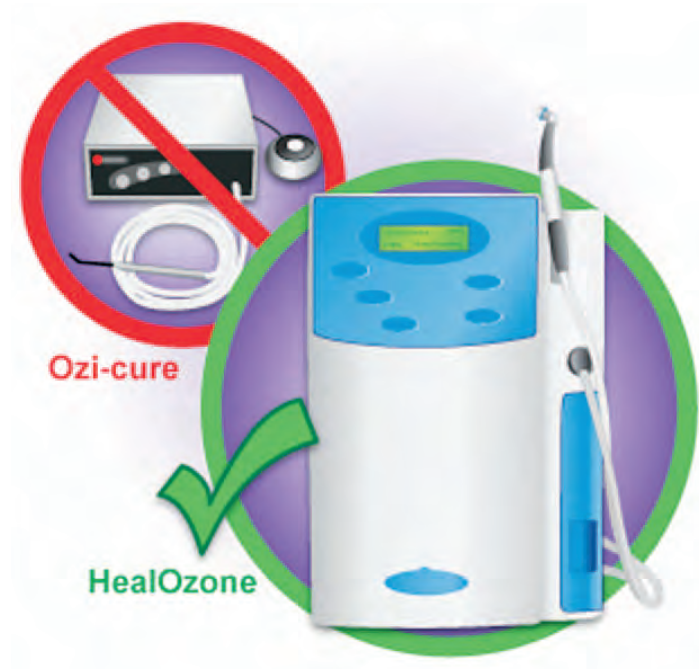

\section{Ozone Therapy in Prosthodontics} Microbial plaque accumulating on the fitted surfaces of dentures is composed of several oral microorganisms, mainly Candida albicans. Denture plaque control is essential for the prevention of denture stomatitis. In an attempt to solve this problem Arita et al. ${ }^{6}$ assessed the effect of ozonated water in combination with ultrasonication on Candida albicans. Following 
exposure to flowing ozonated water (2 or $4 \mathrm{mg} / \mathrm{l}$ ) for one minute they found no viable $C$. albicans suggesting the application of ozonated water might be useful in reducing the number of $C$. albicans on denture bases.

\section{Ozone Therapy in Surgery}

In a clinical survey involving 11 patients Stübinger et al. ${ }^{7}$ described the local effectiveness of ozone on infected intraoral wounds following high-dose radiotherapy.

Guerra et al. ${ }^{8}$ compared the use of ozonated oil (Oleozon, Cuba) in an experimental group to a control group in which Alvogil and antibiotic therapy was used in the treatment of alveolitis. Patients treated with Oleozon healed more quickly without the need for systemic medication when compared to the control group. This finding suggests ozonated oil might be effective in the treatment of alveolitis.

\section{Ozone Therapy and Dental Caries}

Ozone therapy holds great potential as an atraumatic treatment modality to incorporate into dental practice. Some of the available studies assessed the effect of ozone on pit and fissure caries, ${ }^{9}$ non-cavitated occlusal carious lesions, ${ }^{14}$ and primary root caries ${ }^{9,10,11,12}$ with results showing significant reductions in the number of microorganisms in the carious lesions in vitro with short-term follow up.

Ozone therapy was introduced as a conservative alternative in the treatment of primary caries when HealOzone, an ozone-generating device, was used to apply ozone gas to carious lesions for a period of ten to 20 seconds in vivo resulting in the reduction of the number of microorganisms present in the lesions by $99 \% .{ }^{11,12}$

Factors related to the reversal of carious lesions must include the size and localization. The total number of microorganisms in small, non-cavitated lesions showed a greater reduction after the application of ozone than did larger lesions, and lesions closer to the gingival margin also showed less reduction in the number of microorganisms. ${ }^{10}$

Polydorou et al. ${ }^{13}$ evaluated the antibacterial activity of two different HealOzone application times (40 and 80 seconds) on a in vitro tooth cavity model by comparing the ozone antibacterial activity with two dentin-bonding agents. Human teeth were divided into five groups of seven teeth each. Enamel was removed from the occlusal part of the teeth and four cylindrical cavities were prepared using a diamond bur without causing pulp exposure. Then the cavities were filled with $10 \mu \mathrm{L}$ of Streptococcus mutans suspension. Three of the cavities in each tooth were used as experimental cavities and one as a control for the dentin infection. The cavities were treated according to the group to which they belonged: the cavities of the control group were untreated (group A), Clearfil SE Bond (group B), Clearfil Protect Bond (group C), and 40 (group D) and 80 seconds (group E) of ozone were applied, respectively. The results showed the two antibacterial treatments significantly reduced the levels of Streptococcus mutans as compared to the control. However, application of ozone for 40 seconds was less effective than the other three groups. According to the methods applied 80-second ozone application using the HealOzone device is a very promising therapy for eliminating residual microorganisms in deep cavities.

On the other hand, an in vitro study by Baysan et al. ${ }^{14}$ assessed the antimicrobial effect of the application of ozone gas on the microflora of infected dentin associated with non-cavitated occlusal carious lesions. They subsequently determined the effect of ozone gas on the viability of bacteria in the exposed infected dentin associated with these lesions. The ozone failed to reduce the number of viable bacteria in the underlying infected dentin suggesting the mechanism of action of ozone on bacteria occurs in an indirect manner.

Celiberti et al. ${ }^{15}$ assessed the influence of ozone on enamel prior to etching and sealing. The results indicated ozone had no influence on the physical properties of the enamel to enhance or hinder the sealing ability. Thus, ozone can be applied over intact and prepared enamel during the restoration process.

\section{Ozone Therapy in Periodontics}

Nagayoshi et al. ${ }^{16}$ examined the effect of ozonated water on oral microorganisms and dental plaque. Almost no oral microorganisms were detected 
after a ten second treatment with ozonated water $(4 \mathrm{mg} / \mathrm{L})$. When the experimental dental plaque was exposed to ozonated water, the number of viable cells once again decreased. The ozonated water strongly inhibited the formation of dental plaque in vitro. These results suggest ozonated water may be useful in reducing infections caused by microorganisms present in dental plaque.

Huth et al. ${ }^{17}$ in an in vitro study evaluated whether gaseous or aqueous ozone has any toxic effect on human oral epithelial and gingival fibroblast cells in comparison with established antiseptics (chlorhexidine digluconate $2 \%$ and $0.2 \%$; sodium hypochlorite $5.25 \%$ and $2.25 \%$; and hydrogen peroxide $3 \%$ ) during a 1-minute time period and then compared with metronidazole over 24 hours. The investigators found ozone gas to be toxic to the cell lines and aqueous ozone was more biocompatible than gaseous ozone.

\section{Ozone Therapy in Endodontics}

Polymicrobial infections complicate cases of apical periodontitis. As a result, current research is focused on finding treatment solutions with a high antimicrobial effect while mimimizing injury to the periapical tissues.

The oxidative power of ozone characterizes it as an efficient antimicrobian and its indication for use in endodontic therapy seems quite appropriate. Its antimicrobial action has been demonstrated against bacterial strains such as: Micobacteria, Staphylococcus, Streptococcus, Pseudomonas, Enterococcus and Escherichia coli (Seshi et al. ${ }^{18}$ ), Staphylococcus aureus (Velano et al. ${ }^{19}$ ), Enterococcus faecalis (Hems et al. ${ }^{20}$ ), and Candida albicans (Arita et al.6) using in vitro research models.

Pereira ${ }^{21}$ evaluated the radiographic, histopathological, and histobacteriological effects of intracanal medication using ozonated oil compared to a calcium hydroxide paste associated with camphorated paramonochlorophenol and glycerin (HPG) for the endodontic treatment of teeth with periapical lesions. The analysis failed to reveal significant differences between periradicular tissue responses to both medications suggesting ozonated oil may be used in endodontics as an intracanal medication.
Nagayoshi et al. ${ }^{22}$ evaluated the effect of ozonated water on Enterococcus faecalis and Streptococcus mutans in contaminated bovine teeth. A significant intratubular decrease of these bacteria was observed. This improved following mechanical agitation, approximating the effect of ozonated water to that of $2.5 \%$ sodium hypochlorite. The cytotoxicity of ozonated water on rat fibroblasts was also evaluated. The metabolic activity of fibroblasts was higher when treated with ozonated water while there was a decrease in these cells when exposed to sodium hypochlorite.

Hems et al. ${ }^{20}$ evaluated the antimicrobial potential of ozone gas on isolated strains of Enterococcus faecalis. Biofilms incubated for 240 seconds with ozonated water showed no reduction in the microflora. Therefore, ozone has an antimicrobial effect on planktonic Enterococcus faecalis but has little effect when this bacterium is organized in biofilm.

Cardoso $^{23}$ evaluated the efficiency of ozonated water as an irrigating agent during endodontic treatment in an attempt to eliminate Candida albicans and Enterococcus faecalis and to neutralize lipopolysacharides (LPS) inoculated in root canals. It was possible to see effective antimicrobial action after ten minutes of water ozonization on the microbial suspension. There was no residue found when a second sample was collected seven days later. However, ozonated water was not able to neutralize E. coli and LPS inside root canals and the remaining amount of LPS may have biological consequences such as apical periodontitis.

Estrela et al. ${ }^{24}$ assessed the antimicrobial efficiency of aqueous ozone, gaseous ozone, $2.5 \%$ sodium hypoclorite, and $2 \%$ chlorexidine in human root canals infected with Enterococcus faecalis. None of the solutions tested were found to be effective against the bacterial suspension.

\section{Stomatology}

Sechi et al ${ }^{18}$ evaluated the effect of ozonized sunflower oil on different bacterial species isolated from different sites. Oleozon proved to be effective against all bacteria tested, while micobacteria were shown to be the most susceptible to the oil. 
Macedo and Cardoso ${ }^{25}$ described a case report of the application of ozonated oil on herpes labialis and mandibular osteomyelitis and demonstrated faster healing times than conventional protocols.

\section{Discussion}

Since its introduction in 1840, ozone therapy is proving to be a new therapeutic modality with great benefits for patients. The potent antimicrobial power of ozone, along with its capacity to stimulate the circulatory system and modulate the immune response, makes it a therapeutic agent of choice in the treatment of over 260 medical pathologies, ${ }^{1,2}$ among them Hepatitis, Herpes simplex, Herpes zoster, circulatory system dysfunctions, immune diseases, and others. ${ }^{1,2,3}$

Current research has been focused on determining guidelines for ozone use. The principle line of study has evolved using the HealOzone device to determine its effect on several kinds of caries (pit and fissure, ${ }^{9}$ noncavity, ${ }^{11-14}$ and primary root caries ${ }^{9-12}$ ). The oxidative impact on this microbiota has been recognized in several studies, ${ }^{10-14}$ however, there is a divergence of opinion regarding the amount of time that ozone gas should be applied. ${ }^{26}$ One study suggests application of ozone gas for a period of ten to 20 seconds resulted in $99 \%$ of the microorganisms being destroyed. ${ }^{10}$ Another report states 40 seconds of application was insufficient to decontaminate the area and failed to act on underlying infected dentin. ${ }^{14}$ Interesting data shows ozone does not affect the sealing ability of the bonding-system. ${ }^{15}$

In endodontics the ozone showed effetiveness over most of the bacteria found in cases of pulp necrosis, ${ }^{19,21-24}$ but not when the bacteria are organized in biofilm ${ }^{20}$ in in vitro studies.

Such divergency of study outcomes may be related to methodological differences linked to the lack of in vitro and in vivo long-term, randomized, controlled trials and double blind studies. ${ }^{26}$

\section{Conclusion}

For the reasons discussed, the future of ozone therapy must focus on the establishment of safe and well-defined parameters in accordance with randomized, controlled trials to determine the precise indications and guidelines in order to treat various medical and dental pathologies.

Scientific support, as suggested by demonstrated studies, for ozone therapy presents a potential for an atraumatic, biologically-based treatment for conditions encountered in dental practice.

\section{References}

1. Viebahn-Haensler R. The use of ozone in medicine. 4th ed, 2002.

2. Bocci V. Oxygen-ozone therapy: a critical evaluation, 2002.

3. Nogales CG. [Ozonetherapy: Medical and Dentistry application] [Dissertation]. São Paulo (Brazil): University of São Paulo; 2006.

4. Bocci V. Ozone as Janus: this controversial gas can either toxic or medically useful. Mediators Inflamm. 2004; 13(1):3-11.

5. Millar BJ, Hodson N. Assessment of the safety of two ozone delivery devices. Journal of Dentistry 2007; 37:195-200.

6. Arita M, Nagayoshi M, Fukuizumi T, Okinaga T, Masumi S, Morikawa M. Microbicidal efficacy of ozonated water against Candida albicans adhering to acrylic dentures plates. Oral Microbiology and Immunology 2005; 20:206-10.

7. Stübinger S, Sader R, Felippi A. The use of ozone in dentistry and maxillofacial surgery: A review. Quintessence International 2006; 37(5):353-359.

8. Guerra OC, Cepero SM, Jordan MEM, Vazquez TC. Aplicación de la ozonoterapia en el tratamiento de la alveolitis. Revista Cubana de Estomatologia 1997; 34(1):21-4.

9. Brazzelli M, McKenzie L, Fielding S, Fraser C, Clarkson J, Kilonzo M, Waugh N. Systematic review of the effectiveness and cost-effectiveness of HealOzone for the treatment of occlusal pit/fissure caries and root caries. Health Technology Assessment 2006; 10(16): iii-iv, ix-80.

10. Baysan A, Whiley R, Lynch E. Anti microbial effects of a novel ozone generating device on microorganisms associated with primary root carious lesion in vitro. Caries Res. 2000; 34:498-501. 
11. Baysan A, Lynch E. The use of ozone in dentistry and medicine. Primary Dental Care 2005; 12(2):47-52.

12. Baysan A, Lynch E. The use of ozone in dentistry and medicine. Part 2. Primary Dental Care 2006; 13(1):37-41.

13. Polydorou O, Pelz K, Hahn P. Antibacterial effect of an ozone device and its comparison with two dentin-bonding systems. Eur J Oral Sci. 2006; 114:349-353.

14. Baysan A, Beighton D. Assessment of the ozone-mediated killing of bacteria in infected dentine associated with non-cavitated occlusal carious lesions. Caries Res. 2007; 41:337-341.

15. Celiberti $P$, Pazera $P$, Lussi $A$. The impact of ozone treatment on enamel physical properties. Am J Dent. 2006; 19(1):67-72.

16. Nagayoshi M, Kitamura C, Fukuzumi T, Nishihara T, Terashita M. Efficacy of ozone on survival and permeability of oral microorganisms. Oral Microbiology and Immunology 2004; 19:240-6.

17. Huth KC, Jacob FM, Saugel B, Cappello C, Paschos E, Hollweck R, Hickel R, Brand K. Effect of ozone on oral cells compared with established antimicrobials. European Journal of Oral Sciences $2006 ; 114: 435-440$.

18. Sechi LA, Lezcano I, Nunez N, Espim M, Duprè I, Pinna A. Antibacterial activity of ozonized sunflower oil (Oleozon). Journal Applied Microbiology 2001; 90:279-84.

19. Velano HE, Nascimento LC, Barros LM, Panzeri H. [In vitro evaluation of the antibacterial activity of ozonized water against Staphylococcus aureus] Pesquisa Odontológica Brasileira 2001; 15(1):18-22.

20. Hems RS, Gulabivala K, Ng YL, Ready D, Spratt DA. An in vitro evaluation of the ability of ozone to kill a strain of Enterococcus faecalis. Int Endod J. 2005; 38:22-9.

21. Pereira AMVS. [Comparison of the effects of HPG paste (calcium hydroxide, camphorated paramonochlorophenol and glycerine) or ozonized oil used as intracanal medicaments in the treatment of pulpless teeth associated with periradicular lesions: a radiographic, histopathological and histobacteriological study in dogs.] [PhD thesis] Rio de Janeiro, Brazil: Faculdade de Odontologia da Universidade Federal do Rio de Janeiro; 2002.

22. Nagayoshi M, Kitamura C, Fukuzumi T, Nishihara T, Terashita M. Antimicrobial effect of ozonated water on bacteria invading dentinal tubules. J Endod. 2004; 30(11):778-81.

23. Cardoso MG [Study of the ozonized water efficiency as irrigating solution to eliminate Candida albicans, Enterococcus faecalis and endotoxin from root canal]. (PhD thesis). São José dos Campos: Faculdade de Odontologia de São José dos Campos, Brazil: Universidade Estadual Paulista; 2006.

24. Estrela C, Estrela CRA, Decurcio DA, Hollanda ACB, Silva JA. Antimicrobial efficacy of ozonated water, gaseous ozone, sodium hypochlorite and chlorhexidine in infected human root canals. Int Endod J. 2007; 40:85-93.

25. Macedo SB, Cardoso CC. [The use of ozone in Dentistry]. $16^{\circ}$ Campinas International Conclave $2005 ; 115$.

26. Rickard GD, Richardson R, Johnson T, McColl D, Hooper L. Ozone therapy for the treatment of dental caries. Cochrane Database Systemic Review 2004; 3:CD004153. 
About the Authors

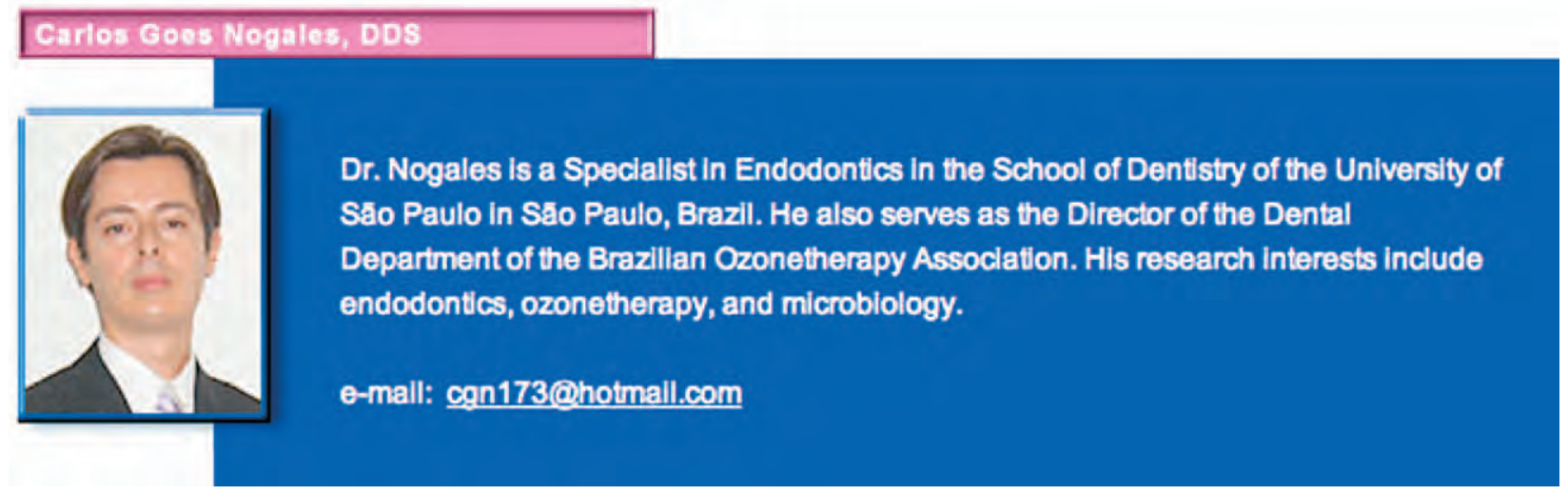

\section{Patricla Holona Forrarl, DDS, Ms, PhD}

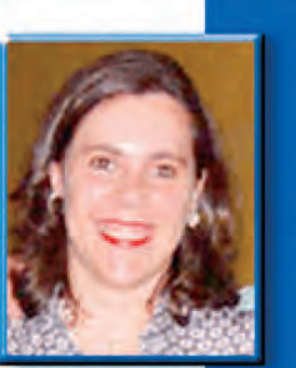

Dr. Ferrari is a Speciallst in Endodontics in the School of Dentistry of the Universidade Estadual Paulista (UNESP) in Araraquara, Săo Paulo, Brazll. Her research Interests are in endodontics and microblology.

o-mall: patferrari@uol.com.br

\section{Efraim Olezower Kantorovich, DDS}

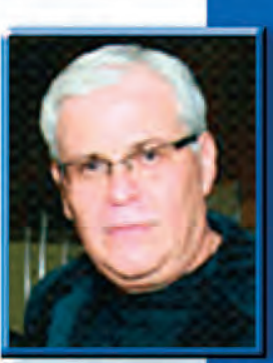

Dr. Kantorovich is a Specialist in Internal Medicine, cardlology, and complementary medicine; and serves as the Clinical Director of the International Center In Preventive Medicine (CMP) in Sao Paulo, Brazll. He is also the Editorlal and Sclentific Director of the Medlcal Biochemistry Joumal. His research interest is in orthomolecular medicine.

e-mall: efraorto@terra.com.br

\section{Jose Lulz Lage-Marques, DDS, M5, PhD}

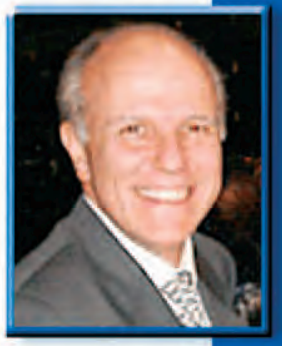

Dr. Lage-Marques is an Associate Professor in the School of Dentistry at the University of Salo Paulo In Salo Paulo, Brazll and he is also a Titular Professor at the University of Taubaté in Taubaté, Săo Paulo, Brazll. Dr. Lage-Marques also serves as a Reglonal Board Member of the IADR.

e-mail: lage@usp.br 